ANELISE PASCHOAL GARCIA DUARTE

PROPOSTAS PARA O TRATAMENTO ESTRUTURAL-ORGANIZATIVO DA CORRUPÇÃO EMPRESARIAL: O PAPEL DO CONSELHO FISCAL

Dissertação de Mestrado

Orientador: Professor Titular Dr. Calixto Salomão Filho

UNIVERSIDADE DE SÃO PAULO

FACULDADE DE DIREITO

SÃO PAULO 
ANELISE PASCHOAL GARCIA DUARTE

\title{
PROPOSTAS PARA O TRATAMENTO ESTRUTURAL-ORGANIZATIVO DA CORRUPÇÃO EMPRESARIAL: O PAPEL DO CONSELHO FISCAL
}

\begin{abstract}
Dissertação apresentada à Banca Examinadora do Programa de PósGraduação da Faculdade de Direito da Universidade de São Paulo, como exigência parcial para obtenção do título de Mestre em Direito, na área de concentração de Direito Comercial, sob orientação do Professor Titular Dr. Calixto Salomão Filho.
\end{abstract}

UNIVERSIDADE DE SÃO PAULO

FACULDADE DE DIREITO

SÃO PAULO

2019 
Duarte, Anelise Paschoal Garcia.

Propostas para o tratamento estrutural-organizativo da corrupção empresarial: o papel do conselho fiscal/ Anelise Paschoal Garcia Duarte; Orientador: Calixto Salomão Filho, São Paulo, 2019.

201.

Dissertação (Mestrado - Programa de Pós-Graduação em Direito Comercial) - Faculdade de Direito, Universidade de São Paulo, 2019.

1. Corrupção. 2.Teoria econômica da corrupção. 3. Governança corporativa. 4. Conselho fiscal. 
DUARTE, Anelise Paschoal Garcia. Propostas para o tratamento estruturalorganizativo da corrupção empresarial: o papel do conselho fiscal. 2019. 201 p. Dissertação de Mestrado. Faculdade de Direito da Universidade de São Paulo, São Paulo, 2019.

\section{RESUMO}

Esta dissertação de mestrado tem por objeto a proposição de soluções estruturaisorganizativas para neutralizar os desequilíbrios nas relações internas de poder entre os órgãos societários. Por esse mecanismo, busca-se criar um ambiente menos propício ao cometimento de atos contra a administração pública pelas companhias brasileiras. Por meio da revisão da literatura a respeito do bem jurídico tutelado pela corrupção e da evolução da teoria econômica da corrupção, que culminaram na proliferação das legislações anticorrupção ao redor do mundo, buscou-se subsídios para identificação das premissas a serem observadas na formulação das propostas apresentadas neste trabalho. Sobretudo, buscou-se afastar de padrões internacionais não aderentes à realidade das companhias brasileiras, bem como de propostas não adequadas, necessárias ou proporcionais em sentido estrito. Como resultado da análise doutrinária e legislativa, propõe-se o fortalecimento do conselho fiscal, como órgão central de controle e fiscalização da legalidade dos atos praticados em nome e por meio das companhias. Para alcançar uma atuação fiscalizatória efetiva, apresentam-se instrumentos que possam garantir sua independência e exercício pleno de suas competências.

Palavras-chave: corrupção, teoria econômica da corrupção, governança corporativa, conselho fiscal. 
DUARTE, Anelise Paschoal Garcia. Projects for a structural and organizational addressment of corporate corruption: the role of the fiscal council. 2019. 201 p. Master's in Law Thesis. Faculty of Law of the University of São Paulo, São Paulo, 2019.

\begin{abstract}
This Master of Laws thesis aims to propose possible structural-organizational solutions to neutralize the imbalances in the internal relations of power between the corporate bodies. By this mechanism, it is sought to create an environment less permissive to the commission of acts against the public administration by the Brazilian companies. Through a review of the literature on the legal interest protected by typifying the crime of corruption and the evolution of the economic theory of corruption that culminated in the proliferation of anti-corruption legislation around the world, we sought subsidies to identify the premises to be observed in the formulation of proposals presented herein. Above all, we sought to move away from international standards not adhering to the reality of Brazilian companies, as well as proposals that are not adequate, necessary or proportional in the narrow sense. As a result of the literature and legislation analysis, it is proposed to strengthen the fiscal council, as the central body for control and oversight of the legality of the acts performed on behalf and through the companies. In order to confer the fiscal council an effective supervision role, we present some mechanisms that shall guarantee its independence and the full exercise of its competencies.
\end{abstract}

Keywords: corruption, economic theory of corruption, corporate governance, fiscal council. 


\title{
PROPOSTAS PARA O TRATAMENTO ESTRUTURAL ORGANIZATIVO DA CORRUPÇÃO EMPRESARIAL: O PAPEL DO CONSELHO FISCAL
}

\author{
SUMÁRIO
}

INTRODUÇÃO 9

\begin{abstract}
PARTE I - IDENTIFICAÇÃO DO BEM JURÍDICO TUTELADO PELO CRIME DE CORRUPÇÃO E LIMITES PARA FORMULAÇÃO DE PROPOSTAS PARA SEU COMBATE E PREVENÇÃO.................................................................................. 20
\end{abstract}

CAPÍtUlo I - O BEM JURÍdico TUTELAdo PELO CRIME DE CORRUPÇÃO E AS LEGISLAÇÕES ANTICORRUPÇÃO..................................... 20

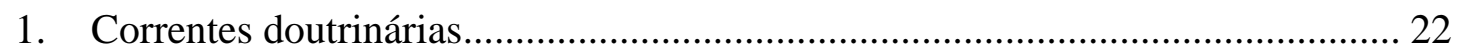

1.1 A administração pública e a capacidade funcional do Estado como bem

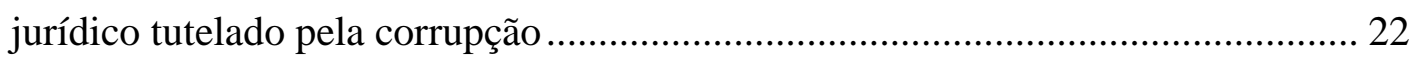

1.2 A democracia como bem jurídico tutelado pela corrupção ......................... 23

2. Normas que regulam a tipificação do crime de corrupção e a responsabilização

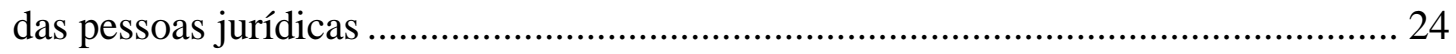

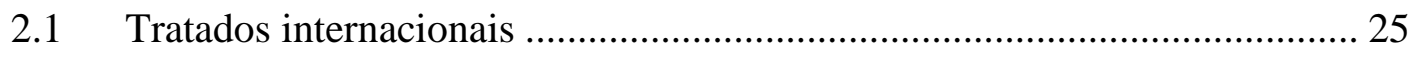

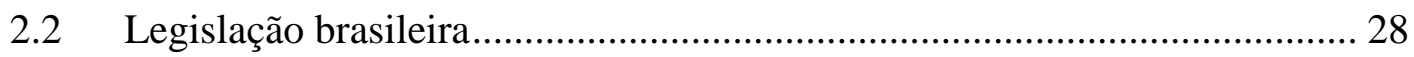

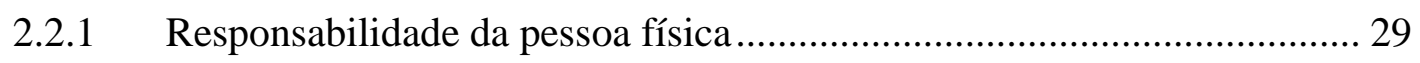

2.2.2 Responsabilidade da pessoa jurídica ................................................ 32

3. Contribuição da Comissão de Valores Mobiliários para o combate à corrupção 40

3.1 Normas de prevenção à lavagem de dinheiro............................................ 40

3.2 Informe de Governança Corporativa.................................................... 42

3.3 Normas sobre transparência, publicidade e deveres de administradores e

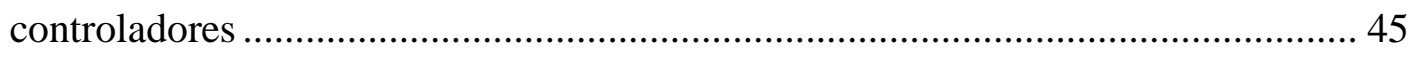

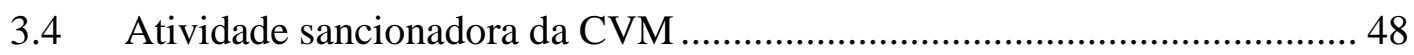

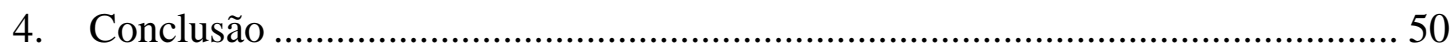




\section{CAPÍTULO II - A EVOLUÇÃO DA TEORIA ECONÔMICA DA CORRUPÇÃO: CONTRIBUIÇÕES PARA A CRIAÇÃO DE INSTRUMENTOS EFETIVOS DE PREVENÇÃO DO FENÔMENO PELAS COMPANHIAS......................................... 53}

1. Panorama geral da análise econômica da corrupção ......................................... 53

2. Estudos sobre benefícios da corrupção para o desenvolvimento econômico....... 55

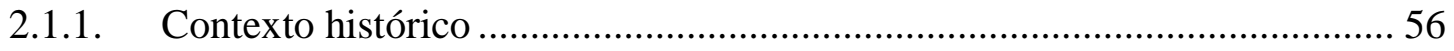

2.1.2. Aparentes benefícios da corrupção ............................................................ 58

2.1.3. Falhas dos argumentos sobre impactos negativos da corrupção ................... 62

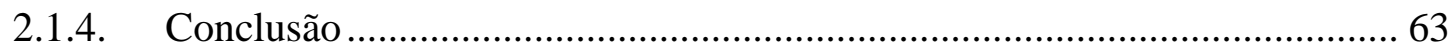

3. Estudos sobre os prejuízos da corrupção para o desenvolvimento...................... 67

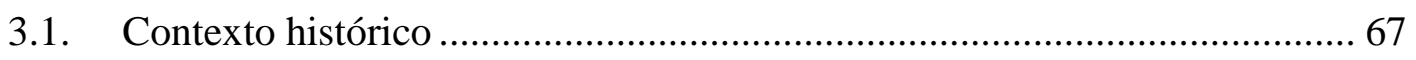

3.2. Estudos sobre potenciais evidências dos prejuízos causados pela corrupção ao desenvolvimento econômico .......................................................................... 70

4. A corrupção como um problema de ação coletiva .............................................. 76

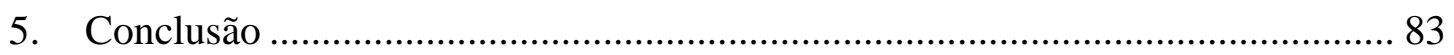

PARTE II - O TRATAMENTO ESTRUTURAL-ORGANIZATIVO DA CORRUPÇÃO EMPRESARIAL ..................................................................................... 87

\section{CAPÍTULO III - PREMISSAS PARA FORMULAÇÃO DE INSTRUMENTOS ESTRUTURAIS-ORgANIZATIVOS PARA PREVENÇÃO DA CORRUPÇÃO PELAS COMPANHIAS

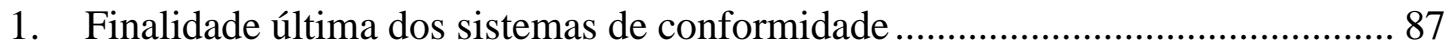

2. Vinculação entre as soluções propostas e características de seus destinatários .. 90

3. Atualização constante das propostas sugeridas ................................................. 91

4. Incentivos para implementação das soluções propostas: entre a cogência da norma e a flexibilidade na adaptação e atualização ................................................. 93

4.1. Limitações do mecanismo de "comply or explain" ........................................ 96

5. Teste de proporcionalidade das propostas sugeridas ........................................ 100

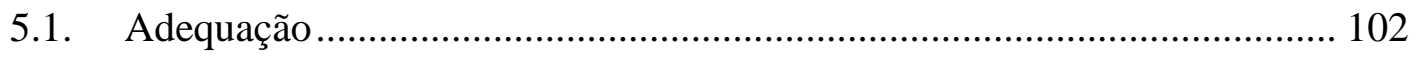

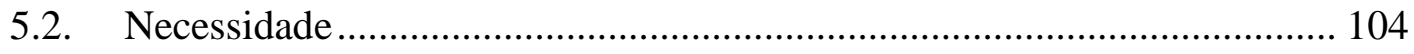




\section{CAPÍTULO IV - OS INSTRUMENTOS PARA REEQUILÍBRIO DAS RELAÇÕES ENTRE OS ÓRGÃOS DA COMPANHIA COMO MECANISMOS EFETIVOS DE PREVENÇÃO À CORRUPÇÃO

1. Introdução

2. Finalidade dos programas de conformidade e sua relação com padrões de governança corporativa

3. O comparativo entre os três poderes do Estado e os órgãos societários.

1.1 Teoria de Hebert Wiedemann, o comparativo brasileiro e o histórico do surgimento da fiscalização interna nas empresas....

1.2 A comparação entre o conselho de administração e o conselho fiscal e o judiciário.

2. O Conselho fiscal: O que é? O que tem sido? O que deveria ser?

2.1 O conselho fiscal na legislação brasileira

2.1.1 Composição

2.1.2 Competência e funcionamento

2.1.3 A oportunidade perdida nas alterações legislativas

2.2 O comitê de auditoria sob o Sarbanes-Oxley Act versus o conselho fiscal reformulado

2.3 A concentração da competência fiscalizatória no conselho fiscal

2.4 Características de um conselho fiscal eficaz

2.4.1 Composição: independência na indicação e atributos necessários dos membros

2.4.2 Remuneração e autonomia orçamentária.............................................. 160

2.4.3 Competência e prerrogativas para assegurar seu exercício .................... 164

2.4.4 Vinculatividade das decisões......................................................... 170

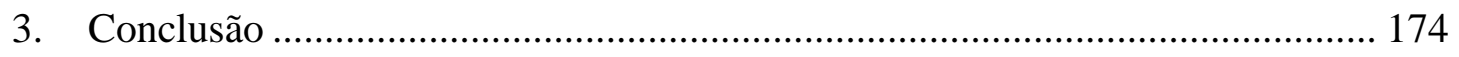

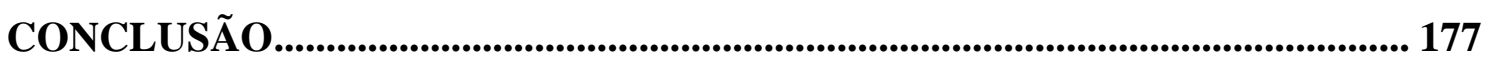

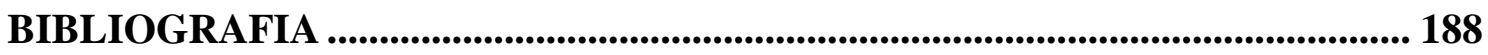




\section{INTRODUÇÃO}

O tema proposto para o desenvolvimento de dissertação de mestrado consiste na proposição de soluções estruturais-organizativas para neutralizar os desequilíbrios nas relações internas de poder entre os órgãos societários, de modo a criar um ambiente menos propício ao cometimento de atos contra a administração pública ${ }^{1}$ pelas companhias brasileiras ("Tema") ${ }^{2}$.

A corrupção, entendida como a manifestação de uma utilização desviada de poder, que dirige seu exercício a benefício próprio ou de terceiros ${ }^{3 \mathrm{e}} 4$, é, atualmente, um dos temas mais caros à humanidade, haja vista os efeitos deletérios que causa aos sistemas democráticos e ao bom funcionamento do mercado.

A maior parte dos juristas contemporâneos entende que o bem jurídico tutelado pelo crime de corrupção é a capacidade funcional do Estado 5 . E, desenvolvendo a ideia, pode-se defender que, em última análise, o que se visa preservar por meio das normas penais, administrativas e civis contra a corrupção, é o contrato social. Este entendido como o acordo original celebrado entre os cidadãos, em que estes entregam parcela de sua liberdade, em prol da organização de uma sociedade gerida por regras comuns a todos.

Nesse sentido, um ambiente viciado pela corrupção, é um ambiente em que as normas perdem a premissa de universalidade e sua aplicação passa a se dar conforme a

\footnotetext{
${ }^{1}$ Neste trabalho, por “corrupção" ou "corrupção empresarial” entender-se-á, quaisquer atos ilícitos praticados por entidades privadas contra a administração pública nacional ou estrangeira.

${ }^{2}$ A identificação de desequilíbrios nas relações internas de poder, bem como as soluções propostas neste trabalham são destinadas às sociedades anônimas brasileiras, reguladas pela Lei n. ${ }^{\circ} 6.404$, de 15 de dezembro de 1976 ("Lei das Sociedades Anônimas").

${ }^{3}$ SILVEIRA, Renato de Mello Jorge. A ideia penal sobre a corrupção no Brasil: da seletividade pretérita à expansão de horizontes atual. Estudios Sobre La Corrupción Una Reflexión Hispano Brasileña, Salamanca: Universidade de Salamanca, 2013, p. 80.

${ }^{4}$ Outra definição útil e precisa de corrupção, que abrange o apecto do fenômeno que se quer endereçar neste trabalho é de Nathaniel H. Leff: "Corruption is an extra-legal institution used by individuals or groups to gain influence over the actions of the bureaucracy. As such, the existence of corruption per se indicates only that these groups participate in the decision-making process to a greater extent than would otherwise be the case." LEFF, Nathaniel H. Economic Development through Bureaucratic Corruption. The American Behavioral Scientist. November, 1964, p. 8.

5"No especial caso da corrupção, seu espectro é amplíssimo, podendo ser modulado conforme a corrupção que se esteja a tratar. Sinteticamente, no que diz respeito à clássica tipificação codificada, outra sorte não se verifica. Não se pode simplisticamente imaginá-lo como a Administração Pública, mas, sim, como a capacidade funcional do Estado." SILVEIRA, Renato de Mello Jorge. A ideia penal sobre a corrupção no Brasil: da seletividade pretérita à expansão de horizontes atual. Estudios Sobre La Corrupción Una Reflexión Hispano Brasileña, Salamanca: Universidade de Salamanca, 2013, p. 84.
} 
conveniência dos vencedores nos jogos de poder. Exatamente por essa insegurança e ausência de universalidade causada pela corrupção, para além de objeto de análise da sociologia política, o tema passou a ser estudado por especialistas interessados em identificar a relação entre o fenômeno e o funcionamento da economia.

Em meados de 1960, idealizadores da chamada teoria econômica da corrupção, criada com a finalidade de apresentar uma análise moralmente isenta do fenômeno, chegaram a sustentar que, sob dadas circunstâncias, a corrupção poderia ser benéfica ao desenvolvimento econômico de algumas nações ${ }^{6}$.

Com a evolução da teoria, surgimento de outros interesses, em meados de 1990, estudiosos passaram a argumentar exatamente o contrário e, por meio de estudos empíricos, tentaram demonstrar que os altos níveis de corrupção limitam o investimento estrangeiro e o crescimento e levam à ineficiência do governo e subdesenvolvimento das nações $^{7 \mathrm{e} 8}$.

Tais estudos, fortemente influenciados por organismos multilaterais, buscaram demonstrar que o fenômeno da corrupção, ao criar um mercado paralelo em que políticas econômicas, regulatórias e fiscais não são aplicadas a determinados agentes, acaba por gerar extrema insegurança jurídica e injustiça, o que aumenta os custos de transação. Estes custos seriam repassados aos consumidores, trabalhadores e investidores, e criariam

\footnotetext{
${ }^{6}$ No Capítulo II apresentar-se-á de forma detalhada o argumento trazido pelos autores dessa corrente, bem como a influência do contexto histórico (Guerra Fria) que estavam inseridos para formulação das ideias apresentadas.

7 "High levels of corruption limit investment and growth and lead to ineffective government. Developing countries and those making transitions from socialism are particularly at risk, but corruption is a worldwide phenomenon. Corruption creates economic inefficiencies and inequities, but reforms are possible to reduce the material benefits from payoffs. Corruption is not just an economic problem, however; it is also intertwined with politics. Reform may require changes in both constitutional structures and the underlying relationship of the market and the state". ROSE-ACKERMAN, Susan. Corruption and Government: Causes, Consequences and Reform. New York: Cambridge University Press, 1999, p. 1.

${ }^{8}$ A mesma percepção é relatada no Relatório do Institut National des Hautes Études de la Sécurité et de la Justice, Corruption, Concussion, Trafic D'influence, de junho de 2016. "En 2014, la Banque mondiale évalue à 1000 milliards de dollars US le montant de pots-de-vin versés chaque année. La corruption entraînerait une diminution de l'investissement public et privé de l'ordre de $20 \%$. Pour la seule économie européenne, le coût de la corruption est estimé par le Groupe d'États contre la corruption (Greco), dépendant du Conseil de l'Europe, à 120 milliards d'euros. Selon la même source, environ trois quarts des Européens (73\%) affirment que les pots-de-vin et le recours aux relations personnelles constituent souvent le moyen le plus simple d'obtenir certains services publics dans leur pays. De plus, deux Européens sur trois (67\%) estiment que le financement des partis politiques n'est pas suffisamment transparent ni contrôlé."
} 
vantagens para agentes dispostos a corromper, distorcendo as relações de mercado e desestimulando o investimento.

Tamanho protagonismo conferido à análise do fenômeno da corrupção desencadeou um movimento internacional pela proliferação de tratados e legislações internas de combate à corrupção. Foi, então, que diversos países passaram a adotar modelos internacionais de combate ao fenômeno, por meio de introdução de normas de agravamento de responsabilidade penal, civil e administrativa de pessoas físicas e jurídicas que colaborassem para a prática de atos contra a administração pública nacional e estrangeira.

À parte o objetivo louvável do movimento, fato é que, desde o início da proliferação das legislações anticorrupção, da qual o Brasil não foi exceção, já se passaram quase 30 anos e, até o momento, não houve diminuição perceptiva na proliferação do fenômeno.

Ainda, ante a percepção da magnitude dos danos causados pelos crimes de corrupção, há uma crescente preocupação com relação à correta delimitação do cabimento e da eficácia da intervenção jurídico-penal na prevenção e combate desses ilícitos ${ }^{9}$. É indubitável que a responsabilidade penal tem um papel relevantíssimo no combate à corrupção e proteção do bem jurídico tutelado. Porém, igualmente evidente é que essa vertente de responsabilização tem os seus limites.

Nesse sentido, outras áreas do direito têm assumido parte da responsabilidade para, de forma complementar, contribuir para a configuração de uma estrutura de prevenção e combate à corrupção mais efetiva e aderente à realidade.

Nesse contexto, passou-se a identificar quais outras áreas do direito poderiam contribuir para a prevenção e combate da corrupção. Estimuladas, em parte, pela

\footnotetext{
9 “Justamente em razão da ameaça que representam à estrutura social e, assim, à própria democracia, tais questões vêm despertando especial preocupação, avolumando-se nesse contexto os questionamentos sobre o papel e os objetivos do Estado em relação ao pleno desenvolvimento da cidadania. Consequentemente, crescem também os debates sobre os limites de atuação da Administração Pública, assumindo particular importância a análise da legitimidade e do conteúdo da intervenção jurídico-penal no controle da corrupção, bem como dos inúmeros delitos a ela relacionados" BECHARA, Ana Elisa Liberatore S., FUZIGER, Rodrigo José. A política criminal brasileira no controle da corrupção pública. Estudios Sobre La Corrupción Una Reflexión Hispano Brasileña, Salamanca: Universidade de Salamanca, 2013, p. 304.
} 
legislação que atribuiu responsabilidade objetiva às empresas que pratiquem ou contribuam para a prática de atos de corrupção, no âmbito do direito empresarial, passouse a defender a criação de regras internas às empresas para a promoção de valores éticos, prevenção e identificação de cometimento de ilícitos por seus empregados, administradores e prestadores de serviços. Tal regramento interno é comumente chamado de programa de compliance (em português, programas de conformidade ou integridade $^{10}$.

Entretanto, o movimento internacional que incentiva a adoção de programas de conformidade pelas empresas ao redor do mundo parece padecer da mesma falha que o movimento de proliferação de legislações anticorrupção: a replicação acrítica de modelos adotados em outros países, que não têm correlação com as estruturas de poder político e econômico existentes no Brasil, tampouco com as estruturas do mercado de capitais nacional e as principais companhias brasileiras ${ }^{11}$.

\footnotetext{
${ }^{10}$ Há intenso debate acerca de qual seria a nomenclatura mais adequada para identificar o conjunto de regras e mecanismos adotados por empresas para a promoção de valores, prevenção de ilícitos e identificação de irregularidades. Como o Tema deste trabalho delimita-se à formulação de propostas estruturaisorganizativas, que não perpassam pelo julgamento ou análise moral ou ética da atuação individual de empregados e administradores das companhias, entendeu-se mais adequado referir-se a "sistema de conformidade", o que não significa buscar a restrição das propostas à mera rotina de controle de riscos e auditoria. A esse respeito: "Na literatura do ambiente de negócios, Palanski e Yammarino (2009) (...) sugerem a utilização do termo com o sentido de 'uma virtude que não é moralmente boa ou má em si, mas que é necessária para se atingir a retidão moral' (...). Uma forma de resumir integridade é a consistência entre as palavras e a ação. Erhard e Jensen (2012) argumentam que (...) 'Definir integridade como 'honrar a palavra' proporciona um acesso inequívoco e prático para se ter acesso a desempenho superior e vantagem competitiva, tanto no nível individual como no organizacional.' BRANDÃO, Carlos Eduardo Lessa. "Governança corporativa e integridade empresarial: conceitos, atitude e prática" in BRANDÃO, Carlos Eduardo Lessa, FONTES FILHO, Joaquim Rubens; MURITIBA, Sérgio Nunes (org.). Governança corporativa e integridade empresarial: dilemas e desafios. $1^{a}$ ed. São Paulo: Saint Paul Editora, 2017, p. 25 e ss. Em sentido complementar: “(....) abordarei o conceito de integridade pessoal e tentarei defender a tese de que um programa de integridade corporativa deve criar um ambiente de tomada de decisão que, de fato, promovam e façam valer os valores e os princípios assumidos e declarados pela empresa. De meu ponto de vista são tais ambientes que verdadeiramente facilitam as coisas para os conselheiros - e para os executivos - na hora das decisões difíceis e, em consequência disso, diminuem a probabilidade e as situações de risco de ocorrência de atos ilícitos ou antiéticos nas atividades, negócios e operações da empresa. Esses ambientes são os úteros da integridade corporativa e, se forem estéreis, nenhum programa de compliance ou conformidade terá chances reais de ser bem-sucedido - isso significa que programas de integridade são distintos e devem se afastar dos modelos de programas de monitoramento, entre os quais estão os programas de compliance." BARCAT, George. "Um programa de integridade não é um programa de conformidade" in BRANDÃO, Carlos Eduardo Lessa, FONTES FILHO, Joaquim Rubens; MURITIBA, Sérgio Nunes (org.). Governança corporativa e integridade empresarial: dilemas e desafios. $1^{\text {a }}$ ed. São Paulo: Saint Paul Editora, 2017, p. 51.

11 ' $\mathrm{Na}$ verdade, muitas vezes os aprimoramentos, o discurso sobre 'governança' ou os mecanismos de controles internos nem mesmo são criados para responder a essa nova realidade financeira, a esse novo mundo em que as empresas atuam, mas muito mais em resposta a tendências, quase como um reflexo condicionado. E entre não adotar as soluções adequadas ou adotá-las apenas por mimetismo, sem atenção às reais necessidades da empresa e meramente a partir de uma receita pronta, a distância
} 
Nesse contexto, para desenvolvimento do Tema, tentar-se-á analisar de forma crítica de que modo pode o direito societário contribuir de forma mais efetiva e aderente à nossa realidade, para a criação dessa estrutura anticorrupção. Para tanto, propõe-se, primeiramente, identificar de que modo as estruturas internas da companhia e a composição e funcionamento de seus órgãos corroboram, permitem ou perpetuam as relações de poder intrínsecas ao fenômeno da corrupção, de modo a formular propostas que possam contribuir para neutralizar os desequilíbrios encontrados.

Para essa análise, utiliza-se de interessante paralelo apresentado pela doutrina entre os órgãos da companhia e os três poderes do Estado ${ }^{12}$. De forma sucinta, a assembleia geral estaria para o legislativo, a administração para o executivo e o judiciário, na proposta deste trabalho, poderia ser representado pelo conselho fiscal. Desse modo, as soluções para o tratamento estrutural-organizativo da corrupção empresarial estão centradas na capacitação do conselho fiscal, como órgão centralizador da competência fiscalizatória da companhia. Busca-se dotá-lo de independência e atributos suficientes para que exerça de forma eficiente a sua competência na identificação e prevenção do cometimento de ilícitos em nome e por meio da companhia.

Nesse sentido, partindo-se da premissa de que a empresa é um instituto jurídico que agrega um feixe de interesses diversos, os atos de corrupção por ela cometidos não afetam somente seus sócios, e sim todos aqueles grupos que dependem da atividade empresarial, tais como trabalhadores, consumidores, credores, fornecedores e agentes da comunidade em que se insere, os chamados stakeholders. ${ }^{13}$

É nesse contexto que se defende a construção de mecanismos internos de prevenção à corrupção que levem em consideração todos os interesses afetados pela atividade empresarial, com vistas a criar um ambiente menos propício à prática desses

\footnotetext{
parece-me pequena." Manifestação de voto do Diretor Otavio Yasbek na sessão de julgamento do PAS CVM n $18 / 08$, realizada no dia 14 de dezembro de 2010.

12 WIEDEMANN, Hebert. Gesellschaftsrecht I- Grundlagen. Munique: Editora Beck, 1980. Tradução de Erasmo Valladão Azevedo Novaes e França, in Temas de Direito Societário, Falimentar e Teoria da Empresa, Malheiros, 2009. Essa teoria foi analisada com mais detalhes no Capítulo IV.

${ }^{13}$ O termo "stakeholders" utilizado nesse artigo refere-se a todos os grupos sem os quais a empresa deixaria de existir, o que inclui os acionistas, empregados, consumidores, fornecedores, credores e comunidade em que a companhia se insere, conforme definido em memorando do Stanford Research Institute (SRI), em 1963, a qual teria sido, segundo Donaldson e Preston (1995) a primeira vez em que o termo foi empregado. DONALDSON, Thomas; PRESTON, Lee E. The stakeholder theory of the Corporation: concepts, evidence and implications. Academy of Management Review, New York, v. 20, n. 1, p. 65-91, 1995.
} 
ilícitos. Por essa razão, as soluções estruturais, além de serem mais efetivas, por atingirem o fundamento dos problemas identificados, podem direcionar a punição aos grupos de interesses que efetivamente contribuíram para o cometimento dos ilícitos. Dessa forma, uma estrutura de controles internos efetiva, pode contribuir não só para a criação de um ambiente menos propício à prática de atos de corrupção, mas também para a mais fácil e precisa identificação dos indivíduos que contribuíram para a prática de atos de corrupção por meio ou em nome da empresa, de modo a subsidiar a correta aplicação de sanções pelo direito penal, administrativo e civil.

Buscar, então, por meio das estruturas da empresa, promover a neutralização dos desequilíbrios nas relações de poder entre os órgãos da companhia - com o intuito de se criar um ambiente menos propício ao cometimento de ilícitos por meio ou em nome da empresa é, em última análise, garantir os interesses por ela tutelados ${ }^{14}$.

Sabe-se, entretanto, que não é função principal de nenhuma empresa combater a corrupção, de modo que os instrumentos propostos para prevenção do fenômeno devem ser proporcionais $^{15}$ ao objetivo que se visa atingir. Para além de equilibrar os instrumentos destinados ao tratamento da corrupção, atestar a sua proporcionalidade tem a finalidade de garantir que, passados alguns anos de implementação de medidas não adequadas, necessárias ou proporcionais em sentido estrito, surjam estudos e pesquisas

\footnotetext{
${ }^{14}$ À luz de uma visão institucionalista do direito societário, sustenta-se que a função social da empresa vai além da criação de valor para os sócios e deve levar em consideração a consecução dos interesses dos demais grupos afetados pela atividade empresarial. A ideia desenvolvida por Tantalo e Priem no artigo "Value creation through stakeholder synergy" baseada nesse mesmo conceito, vai além, ao defender que, partindo-se do pressuposto que a função da empresa é harmonizar os interesses de todos os seus stakeholders, seria competência dos administradores encontrar soluções que permitam a concretização de todos esses interesses com o menor prejuízo possível aos grupos envolvidos. "In such situations, stakeholder synergy occurs whenever a single strategic action creates new value for two or more essential stakeholder groups simultaneously, without reducing the value obtained by another essential stakeholder group. (...), top managers must function as innovation-seeking entrepreneurs (Kirzner, 1997; Shane and Venkataraman, 2000) by continuously searching for new opportunities to create value for multiple stakeholder groups simultaneously. The aim of this "synergy searching" is to increase the "size of the pie" (Gulati and Wang, 2003; Porter and Kramer, 2011; Priem, 2007) available for two or more stakeholder groups through a single strategic action or an integrated set of actions (...). Therefore, even if economic factors remain at the same level, overall employee utility may be increased by a flexible work week or by more autonomy." TANTALO, C.; PRIEM, R. L. Value creation through stakeholder synergy. Strategic Management Journal, v.37, n.2, p.314-329, 2014.

${ }^{15}$ Conforme detalhado no Capítulo III, por proporcional entendem-se as propostas adequadas, necessárias e proporcionais em sentido estrito, conforme apresentado pelo mecanismo de ponderação de princípios, emprestado do direito constitucional. Nesse sentido vide: ALEXY. Robert. A theory of constitutional rights. Trans. Julian Rivers. Oxford: Oxford University Press, 1985, ALEXY. Robert. On Balancing and Subsumption. Ratio Juris 16 (2003), 433-449. ALEXY. Robert. Constitutional Rights and Proportionality. Journal for Constitutional Theory and Philosophy of Law, REVUS 22, 2014.
} 
empíricas que busquem demonstrar a ineficácia dos programas internos implementados pelas empresas (em replicação de um padrão internacional), bem como eventual correlação entre estes e uma piora no desempenho das companhias ${ }^{16}$.

Tendo em vista o exposto acima, o desenvolvimento do Tema apresenta-se em duas partes: Parte I - Identificação dos bem jurídico tutelado pelo crime de corrupção e limites para formulação de propostas para seu combate e prevenção; e Parte II - O tratamento estrutural-organizativo da corrupção empresarial.

A Primeira Parte é composta dos seguintes capítulos: Capítulo I - o bem jurídico tutelado pelo crime de corrupção e as legislações anticorrupção; e Capítulo II - a evolução da teoria econômica da corrupção: contribuições para a criação de instrumentos efetivos de prevenção. Já a Segunda Parte é composta pelos seguintes capítulos: Capítulo III premissas para formulação de instrumentos estruturais-organizativos para prevenção da corrupção pelas companhias; e Capítulo IV - os instrumentos para reequilíbrio das relações entre os órgãos da companhia como mecanismos efetivos de prevenção à corrupção.

O primeiro capítulo dedica-se à identificação do bem jurídico tutelado pela legislação anticorrupção, por meio de uma revisão teórica dos principais autores que discorreram sobre o tema na literatura penal. Neste mesmo capítulo, analisa-se o arcabouço normativo internacional (tratados internacionais do qual o Brasil é parte) e legislação nacional a respeito da responsabilização das pessoas físicas e jurídicas pelo cometimento de atos contra a administração pública nacional e estrangeira.

Por meio da análise apresentada desse capítulo, percebe-se que a legislação brasileira a respeito do tema já é vasta e prevê mecanismos interessantes e úteis ao tratamento estrutural do fenômeno da corrupção. Resta somente saber se os mecanismos legalmente previstos serão, de fato, implementados.

Nesse capítulo, por exemplo, nota-se o importante papel conferido à Comissão de Valores Mobiliários na supervisão das companhias, seja em decorrência de novas

\footnotetext{
${ }^{16}$ Como se verá do Capítulo II é o que tem ocorrido com a teoria econômica da corrupção que, após quase 60 anos, passa a apresentar estudos que buscam demonstrar novamente, como no passado, a suposta correlação entre legislações anticorrupção e o subdesenvolvimento econômico.
} 
obrigações impostas por lei ou regulamentação para implementação de procedimentos de controle interno (decorrentes da Lei de Lavagem de Dinheiro e do novo Informe de Governança Corporativa, por exemplo), seja por meio da sua competência para supervisão da legalidade da atuação de administradores e controladores das companhias e da sua conformidade com seus deveres fiduciários.

O segundo capítulo, por sua vez, identifica a evolução da teoria econômica da corrupção, desde o início dos estudos dedicados à análise das relações de causa e efeito entre corrupção e desenvolvimento econômico até os dias atuais. Como se verá, da mesma forma como ocorreu nas últimas décadas de estudo e implementação da legislação anticorrupção ao redor do mundo, em replicação a um padrão internacional, procura-se evitar que os programas de conformidade que vem sendo implementados pelas companhias padeçam da mesma falha e, ao replicarem acriticamente modelos internacionais, revistam-se da mesma ineficácia.

Dessa forma, o terceiro capítulo, construído a partir das conclusões advindas da Primeira Parte deste trabalho, discorre a respeito das premissas para formulação de instrumentos estruturais-organizativos para prevenção da corrupção pelas companhias, baseados em duas máximas: (i) a correta delimitação do objetivo a ser perseguido e (ii) procedimento para verificação da adequação, necessidade e proporcionalidade em sentido estrito dos instrumentos sugeridos para compor o sistema de controles internos das companhias.

Se as soluções propostas forem mal implementadas, pouco efetivas, direcionadas a um objetivo secundário ou desproporcionais aos fins que se propõe, em pouco tempo surgirão estudos para tentar demonstrar sua ineficácia, inutilidade ou, até mesmo, prejudicialidade para o desenvolvimento das empresas, de modo a retroceder o avanço até então conquistado.

Embora não seja objeto principal deste trabalho, nesse capítulo tratou-se também, de forma sucinta, da forma como se devem revestir as regras formuladas para o tratamento estrutural-organizativo da corrupção empresarial: se impostas via lei formal, soft law, ou, o que se entente mais adequado, por meio da criação de incentivos, via legislação, para que entidades privadas se fiscalizem mutuamente e que, para manutenção 
de suas relações com seus parceiros comerciais, vejam a necessidade de implementação de instrumentos internos efetivos de prevenção à corrupção, de modo a além de prevenir a prática de ilícitos, transparecer a terceiros a confiança necessária de que se trata de empresa idônea.

Como detalhado no referido capítulo, ao invés de impor instrumentos que até sejam efetivos em determinada realidade, mas que se mostrem inaptos em outras, via legislação formal, ou confiar em mecanismos de soft law, como o modelo de comply or explain, como se houvesse interesse espontâneo dos indivíduos responsáveis pela implementação das medidas sugeridas em fazê-lo, pode se espelhar em legislações como a Lei de Lavagem de Dinheiro. Esta instituiu a obrigação de determinados entes privados de identificar e reportar suspeitas de ilícitos, sob pena de responsabilidade objetiva pelo envolvimento nos ilícitos ${ }^{17}$.

Partindo-se dessas delimitações, o quarto capítulo apresenta sugestões de composição, competência e autonomia do conselho fiscal das companhias para moldá-lo como um efetivo órgão de controle, capaz de contribuir para a prevenção do cometimento de ilícitos pelas empresas, de modo a proteger o interesse de seus stakeholders e o bom funcionamento do mercado, sem, no entanto, prejudicar a perseguição, pelas companhias, de sua função social.

Nesse contexto, a partir da comparação entre os órgãos da companhia e os três poderes do Estado, identifica-se um potencial desequilíbrio entre as relações de poder

\footnotetext{
${ }^{17}$ Inúmeros são os casos de corrupção cuja deflagração ou aprofundamento das investigações contou com relatórios produzidos pelo Conselho de Controle de Atividades Financeiras (COAF) - Relatórios de Informação Financeira, cujas informações base são remitidas pelas entidades privadas obrigadas ao cadastro e reporte de operações suspeitas. O aumento tanto no número de RIFs como no número de comunicações feitas por pessoas obrigadas é substancial e demonstra que, de fato, a legislação tem sido efetiva para estimular a colaboração de entidades privadas na identificação e reporte de operações suspeitas de lavagem de dinheiro, conforme se nota de declaração do presidente da instituição a respeito dos resultados apurados em 2018: "No total histórico, já foram produzidos e encaminhados cerca de 40 mil Relatórios de Inteligência Financeira (RIFs) às autoridades competentes. (...) Destacam-se, dentre os RIFs produzidos em 2018, cerca de 400 que municiaram a Força Tarefa Lava Jato no Paraná e Rio de Janeiro, a operação Cui Bono, Greenfield, Cadeia Velha, bem como aquelas operações destinadas à supressão da capacidade de pagamento de organizações criminosas que atuam dentro e fora dos presídios. (....) Outro dado importante diz respeito a comunicações encaminhadas pelas pessoas obrigadas. Foram também recebidas, no ano de 2018, cerca de 3 milhões comunicações, suspeitas e em espécie, representando crescimento da ordem de $90 \%$ em relação ao ano anterior. O total histórico de comunicações recebidas pelo COAF é de 17 milhões." Disponível em: http://www.fazenda.gov.br/noticias/2018/dezembro/coafdivulga-balanco-das-atividades-de-inteligencia-financeira-realizadas-em-2018. Último acesso em 27 de dezembro de 2018
} 
existentes entre os órgãos da companhia: há uma lacuna de mecanismos que representem freios e contrapesos ao poder desempenhado pela assembleia geral e pela administração nas companhias, sobretudo aquelas de controle acionário concentrado.

Isso pois, os mecanismos de governança corporativa formulados com base na doutrina que originalmente identificou a necessidade de criação de mecanismos capazes de instituir um controle recíproco entre os órgãos societários foram moldados essencialmente para coibir a prática de atos movidos por interesses particulares dos indivíduos que compunham cada um dos órgãos (assembleia geral e administração) ${ }^{18}$, bem como direcionados a uma realidade de controle acionário disperso ${ }^{19}$.

Dessa forma, apresentam-se dois desafios para adaptação dos mecanismos de controle originalmente aventados: (i) a necessidade de coibir a prática de atos que possam representar benefício (imediato) para a própria companhia e não um benefício particular de administrador ou acionista, mas que represente a prática de atos ilícitos, com consequentes prejuízos a todos os stakeholders da companhia, após sua identificação, e à sociedade como um todo, ainda que não identificados; e (ii) a necessidade de adequar-se tanto a uma estrutura de controle acionário disperso, como de controle acionário concentrado, em que a administração decorre ou coincide com os detentores do poder de controle.

Partindo-se, então, da análise das normas que regem o conselho fiscal na Lei das Sociedades Anônimas, buscou-se identificar quais instrumentos relativos à sua composição, competência e funcionamento poderiam ser construídos, dentro do arcabouço normativo atualmente existente, para torná-lo efetivamente capaz de exercer esse papel de órgão de fiscalização que represente efetivo contrapeso à assembleia geral

\footnotetext{
18 Berle e Means apresentaram possíveis desequilíbrios advindos do descolamento entre o direito de propriedade (dos acionistas) e a gestão (pelos administradores) das empresas. BERLE, Adolf e MEANS, Gardiner. The Modern Corporation and Private Property, New York: Macmillan, 1932.

${ }^{19}$ Regras de governança corporativa foram originalmente propostas para endereçar o problema do conflito de agência entre acionistas e administradores, comum em mercados de preponderância de controle acionário disperso - como o norte-americano. É verdade que, no direito brasileiro, buscou-se implementar instrumentos para neutralização desse conflito no âmbito da relação entre acionistas controladores e acionistas minoritários. Porém, para endereçar o novo desafio de coibir a prática de ilícitos em nome ou por meio da companhia, os instrumentos utilizados não são suficientes, conforme detalhado no Capítulo IV. Nesse sentido, vide: MUNHOZ, Eduardo Secchi. Quem deve comandar a companhia? Alocação do poder empresarial: sistema de freios e contrapesos. In Estudos em Homenagem a Modesto Carvalhosa. São Paulo, Saraiva, 2012, p. 505.
} 
e à administração e seja capaz de identificar e prevenir a prática de atos contra a administração pública por meio ou em nome da companhia.

Ressalta-se que as soluções propostas são exemplos de mecanismos que podem ser efetivos no tratamento estrutural-organizativo da corrupção empresarial. Não há, no entanto, a premissa de universalidade dos instrumentos propostos, o que acabaria por contrariar as conclusões deste trabalho, que apontam justamente para a necessidade de criação de mecanismos capazes de promover o reequilíbrio nas relações entre os órgãos de uma companhia que sejam aderentes à sua realidade.

Por fim, finaliza-se o presente trabalho mediante a apresentação das conclusões, na forma de síntese conclusiva, de modo a apresentar de maneira objetiva os resultados advindos da análise legislativa e doutrinária para desenvolvimento do Tema objeto desta dissertação de mestrado, bem como o esqueleto da composição, competência e atributos de um conselho fiscal capaz de exercer de maneira efetiva a competência de fiscalizar os atos praticados por meio ou em nome das companhias. 


\section{CONCLUSÃO}

"Sometimes the real world knocks in the doors of scholars to dismiss their theories" 198.

Finalizadas as análises a que se propôs para desenvolvimento do Tema desta dissertação de mestrado, apresenta-se, a seguir as principais conclusões delas advindas, em forma sumária.

Do Capítulo I - o bem jurídico tutelado pelo crime de corrupção e as legislações anticorrupção, concluiu-se que:

1. O bem jurídico tutelado pelo crime de corrupção e, portanto, norteador das legislações anticorrupção, é a capacidade funcional do Estado Democrático de Direito.

2. O Brasil, como país membro dos principais acordos internacionais a respeito do tema, dispõe de vasta legislação anticorrupção, que prevê tanto a responsabilização penal da pessoa física por crimes de corrupção stricto sensu e delitos correlatos, como a responsabilização objetiva civil e administrativa da pessoa jurídica pelo cometimento dos referidos ilícitos. Não é, portanto, por falta de arcabouço normativo que o fenômeno da corrupção persiste.

3. Reconhece-se na grande maioria dos países, uma tendência de previsão de novos tipos penais, agravamento de penas já existentes, reinterpretação de garantias penais clássicas, flexibilização de regras de imputação, com a pretensão de ver no direito penal a resposta única para um problema tão antigo, enraizado e complexo.

4. A despeito disso, inúmeros criminalistas já se debruçaram acerca da incapacidade ou inadequação da utilização indiscriminada do direito penal para fazer frente a esse problema. De modo que, ao invés de se redimensionar os limites colocados ao direito penal, em desrespeito às garantias penais clássicas, deve-se recorrer à complementação das outras áreas do direito na construção de uma estrutura anticorrupção mais efetiva.

198 PORTUGAL GOUVÊA, Carlos Pagano Botana. The third bank of the river: democracy and its corruption after liberalization reforms in Latin America. Thesis (LL. M.), Harvard Law School, 2004. 
5. A corrupção deve ser identificada e endereçada tanto sob a perspectiva de um problema de conflito de agência (entre principal e agente) como também como problema de ação coletiva (collective problem action). Segundo essa perspectiva, a propagação da corrupção está relacionada com a percepção generalizada dos indivíduos de que se trata de prática comumente praticada e aceita pelos demais indivíduos, de modo que, atitudes são tomadas racionalmente sob a premissa de que todos agem de forma inidônea, não havendo incentivos aparentes para atuação de forma diversa.

6. Trata-se, portanto, de um problema a ser enfrentado por institutos que representem estímulos para implementação de estruturas anticorrupção que rompam as estruturas de poder atualmente existentes, para que as figuras responsáveis pela implementação das mudanças sugeridas tenham interesse em fazê-lo. Ao invés de propor ações que, ao endereçar o fenômeno como um problema exclusivamente de conflito de agência, visem somente coibir a atuação individual de agentes corruptos, por mero agravamento de responsabilização penal, diminuição da discricionariedade de agentes públicos ou da intervenção do Estado no setor privado.

Do Capítulo II - a evolução da teoria econômica da corrupção: contribuições para a criação de instrumentos efetivos de prevenção, concluiu-se que:

7. A teoria econômica da corrupção, originada em meados da década de 1960, propõe uma análise moralmente isenta do fenômeno da corrupção. Dessa forma, buscouse superar o preconceito que envolve o tema, para identificar se, sob determinadas circunstâncias, a corrupção traria efeitos positivos ou negativos para o desenvolvimento econômico de um país.

8. Da análise da evolução dessa teoria depreende-se que tanto os estudos conduzidos no início da década de 1960, que preconizavam a existência de benefícios da corrupção para o desenvolvimento econômico de países subdesenvolvidos, como os estudos conduzidos a partir da década de 1980, que - em conclusão diametralmente oposta, passaram a identificar a corrupção como um obstáculo para o desenvolvimento econômico das nações subdesenvolvidas, foram (i) influenciados pelo contexto histórico em que se inseriam e por grupos de interesses específicos; e (ii) conduzidos por observadores externos aos países objeto de análise. 
9. A esse respeito observa-se que os primeiros autores da teoria econômica da corrupção estavam fortemente influenciados pelo contexto da Guerra Fria, de modo que a análise por eles apresentada representava uma justificativa para o apoio dos países capitalistas desenvolvidos às ditaduras instaladas na América Latina, sob o fundamento de que seriam um estágio necessário a ser superado pelos referidos países até que se tornassem democracias liberais maduras.

10. Por outro lado, os autores mais recentes da teoria econômica da corrupção iniciaram o movimento pela proliferação de padrões internacionais de legislação anticorrupção, sob forte influência de investidores estrangeiros, interessados em garantir maior segurança e menor custo para os seus investimentos nos países subdesenvolvidos.

11. A despeito da real intenção que pautou os protagonistas do movimento internacional de combate à corrupção, fato é que as legislações anticorrupção por si só não têm sido suficientes para controlar o fenômeno. Uma das razões encontradas para essa ineficiência é a ausência de correlação entre as propostas formuladas, sob premissa de universalidade, e as estruturas das relações de poder político e econômico existentes nos países que as implementaram.

12. Nesse sentido, da mesma forma como os tratados internacionais e a replicação de legislações nacionais anticorrupção não são suficientes e adequadas para solucionar o problema de corrupção de forma padronizada em todos os países que se submetem a elas, as chamadas regras de conformidade e governança corporativa também não o são. Não se atentar às diferentes estruturas de poder dos mercados e das companhias para a formulação de regras a elas endereçadas é, novamente, ignorar que as premissas são diferentes e, portanto, as soluções propostas também deveriam sê-lo.

13. Reforça-se esse pensamento ao nos depararmos com o ressurgimento de estudos e trabalhos empíricos recentes que buscam fundamentar o argumento de que, em determinados países e sob determinadas circunstâncias, reformas para diminuir a intervenção estatal na economia seriam mais eficientes e deveriam se sobrepor a reformas direcionadas ao combate à corrupção. Fossem essas legislações construídas com base na identificação das estruturas locais do complexo fenômeno da corrupção, talvez passadas 
duas décadas de sua adoção já pudéssemos vislumbrar resultados positivos da diminuição do fenômeno, de modo a coibir o ressurgimento de tais teorias.

14. A despeito de eventuais falhas nas soluções propostas pelos autores da teoria econômica da corrupção, destaca-se uma relevante contribuição trazida pela corrente doutrinária: a identificação de que uma das principais ineficiências da visão moralista e idealista da corrupção seria ignorar a sua existência na formulação das políticas de governo.

15. Deve-se aproveitar esse ensinamento e pautar as propostas para o tratamento estrutural-organizativo da corrupção empresarial com vistas na realidade que pretendem atingir e alterar e não sob a premissa de um ambiente idealmente probo e livre de desequilíbrios e ineficiências inerentes às relações entre os órgãos que compõe as companhias.

Do Capítulo III - premissas para formulação de instrumentos estruturaisorganizativos para prevenção da corrupção pelas companhias, concluiu-se que:

16. A análise da teoria econômica da corrupção contribuiu de forma relevante para a formulação de propostas para tratamento do fenômeno da corrupção pelo direito societário, por meio de mudanças estruturais que permitam o reequilíbrio das relações de poder internas às companhias brasileiras.

17. Em suma, as contribuições resumem-se nos seguintes principais itens: (i) identificação do bem jurídico que se visa tutelar por meio do combate à corrupção; (ii) vinculação necessária entre as propostas formuladas e a identificação das especificidades de seus destinatários; (iii) necessidade de atualização e reformulação constante das propostas; (iv) necessidade de criação de mecanismos de incentivo para a efetiva implementação das propostas sugeridas (de modo a endereçar a corrupção também sob seu aspecto de problema de ação coletiva); e (v) proporcionalidade das medidas sugeridas, ante os objetivos que pautaram sua proposição.

18. Entende-se que a finalidade última dos programas de conformidade, por vezes estruturados por meio de regras de governança corporativa, é o reequilíbrio das relações 
de poder internas à companhia, para manutenção de um sistema de controle efetivo apto a identificar e prevenir o cometimento de ilícitos pela companhia, dentre eles, atos de corrupção.

19. Embora a formulação de regras que, efetivamente, atendam à razão de sua existência pareça ser premissa óbvia, não é raro identificar situações em que esse objetivo deixe de ser perseguido. Comumente, algumas regras comumente replicadas por diversas companhias, por vezes em razão de regulamentação nesse sentido, como por exemplo a criação de códigos de conduta, políticas de treinamento, passam a ser entendidas como finalidades em si mesmas. Quando, na realidade, são meios propostos em um determinado contexto para atingir a finalidade última de existência de uma estrutura de controle interno: a criação de um ambiente menos propício ao cometimento de ilícitos.

20. Esse mesmo equívoco cometido na proliferação de programas de conformidade, também foi identificado no âmbito da evolução das discussões e estudos para implementação de legislações anticorrupção, nos quais, pautados pela premissa de universalidade dos padrões propostos, observou-se a prática equivocada de substituição dos objetivos finais das normas, por sub objetivos (meios), previamente delineados para atingi-lo sob circunstâncias específicas de uma dada realidade identificada pelo formulador do sub objetivo.

21. Quando se comete esse equívoco, passa-se a nortear a criação de estruturas anticorrupção, seja no âmbito de legislações anticorrupção, seja no âmbito da implementação de estruturas de controle interno, não mais com base em sua razão de existência, mas com base em sub objetivos que não se confundem com a razão principal pela qual se consagrou o interesse coletivo pelo combate à corrupção.

22. Isso pois esses sub objetivos nada mais são do que o meio encontrado para alcançar o objetivo principal do combate à corrupção em um dado contexto específico, não sendo adequado confundi-los como um fim em si mesmos, até porque podem não ser adequados ao atingimento do objetivo principal em uma realidade diferente daquela identificada para formulação do plano original. 
23. O desequilíbrio entre os (insignificantes ou inexistentes) benefícios trazidos pela implementação das referidas estratégias, de um lado, e os (relevantes) prejuízos causados em outras searas, por outro, com o tempo, poderão levar a conclusão de que a referida estrutura anticorrupção, nos moldes tal qual proposta, é prejudicial ao desenvolvimento da companhia.

24. Como decorrência da premissa anterior, é de extrema relevância a constante atualização das formulações propostas, de modo a acompanhar as transformações no contexto e conjuntura em que os destinatários das regras propostas se inserem.

25. Para além de acompanhar transformações, a constante atualização das propostas formuladas é essencial ante a constatação de eventual necessidade de realização de novos testes de proporcionalidade diante da identificação de efeitos adversos advindos da implementação das propostas que, porventura, não tenham sido previstos ou contemplados no momento de sua formulação.

26. Tanto a necessária vinculação das propostas formuladas com as características específicas da realidade estrutural que pretende endereçar, como a necessidade de constante revisão e adaptação das propostas formuladas acabam por direcionar para a formalização das regras por um meio que permita certa flexibilidade.

27. Se por um lado, deve-se permitir a construção de regras que enderecem uma realidade específica, por outro, a adaptatividade das propostas formuladas não pode ser acompanhada de um caráter não vinculante.

28. Faz-se, então, necessária a criação de um sistema normativo de incentivo à implementação de regras adaptáveis à realidade de seu destinatário, de modo que não sejam nem comandos objetivos e cogentes - por carecerem da adaptatividade necessária, nem meras sugestões a serem adotadas conforme a conveniência dos indivíduos responsáveis por sua implementação - por carecerem de incentivo à implementação.

29. Uma aparente solução para essa questão parece ser a adoção de sistema semelhante à legislação de prevenção à lavagem de dinheiro, em que se impõe a determinados agentes de setores relevantes para a lavagem de dinheiro (sistema 
financeiro, negociação de valores mobiliários, bens de luxo e alto valor, obras de arte, etc.) a obrigação de reporte de operações realizadas por terceiros que sejam suspeitas de lavagem de dinheiro, sob pena de serem objetivamente responsabilizados pela ausência de comunicação.

30. No âmbito do combate à corrupção pode-se prever a proibição de investimento em companhias condenadas pela prática do ilícito, obrigação de reporte de transações suspeitas (em complemento à lavagem de dinheiro), proibição de concessão de crédito por entidades públicas de fomento, entre outras medidas que criem incentivos para que agentes privados exijam uns dos outros, para manutenção de suas relações comerciais, a implementação de medidas concretas que assegurem, com algum grau de assertividade, medidas de prevenção à corrupção.

31. Tendo em vista a pluralidade de elementos e premissas que se deve levar em consideração para a formulação das propostas de respostas estruturais-organizativas para a corrupção empresarial, emprestou-se do direito constitucional um procedimento largamente difundido pela doutrina para ponderação de princípios, que seriam mandamentos de otimização, em oposição às regras, caracterizadas como comandos definitivos, por meio dos testes de proporcionalidade, que visam identificar a adequação, necessidade e proporcionalidade em sentido estrito das propostas formuladas.

32. Por adequação entende-se a necessidade de identificar se a proposta atende à finalidade última a que se propõe - teste de extrema importância, haja vista a constante confusão entre os objetivos dos programas de conformidade e meios sugeridos para atingi-los.

33. Por necessidade entende-se a identificação de se não haveria alternativa menos custosa, seja em termos pecuniários, seja em termos de restrição de direitos ou interesses afetados, para atingir a mesma finalidade. Esse teste deve ser constantemente repetido e formulado em debates com os mais diferentes interlocutores que podem contribuir com soluções inusitadas, por vezes mais efetivas e menos custosas para atingimento de um mesmo objetivo. 
34. Por proporcionalidade em sentido estrito entende-se a verificação da correlação entre o benefício pretendido mediante a implementação da proposta ante os custos a ela inerentes.

35. Conclui-se, portanto, que o olhar para trás que pautou a análise da doutrina e legislação na Primeira Parte deste trabalho permitiu-nos identificar premissas que, se observadas, na formulação e na avaliação constante dos programas de conformidade das empresas, poderá nos poupar das consequências advindas de eventual repetição dos equívocos cometidos na implementação das legislações anticorrupção, que antecederam esse movimento internacional de promoção do compliance e da governança corporativa.

Do Capítulo IV - os instrumentos para reequilíbrio das relações entre os órgãos da companhia como mecanismos efetivos de prevenção à corrupção, concluiu-se que:

36. O comparativo entre os três poderes do Estado e os órgãos da companhia é relevante para apontar a fragilidade do órgão responsável pela fiscalização e principal contrapeso à atuação dos demais órgãos: o conselho fiscal.

37. Se, por bastante tempo, confiou-se na figura do conselho de administração e nos instrumentos de controle criados para neutralizar desequilíbrios advindos das relações entre acionistas e administradores (sobretudo relacionadas a eventual desvio de suas funções para atendimento de interesses particulares), furtou-se à delineação de instrumentos para permitir o exercício efetivo da competência legalmente conferida ao conselho fiscal, para controle da legalidade de atuação de tais indivíduos.

38. Como principal característica de uma estrutura de controle interno efetiva, sugerese a sua concentração. Assim como foi um importante avanço na legislação societária pátria o reconhecimento da existência do acionista controlador como um centro de imputação de direitos e responsabilidades é essencial que se reconheça um poder de fiscalização central, passível de ser identificado e responsabilizado na falha da condução de suas competências.

39. Isso pois, o que se busca evitar com a concentração da competência fiscalizatória sob um único órgão que compõe a companhia é: (i) o esvaziamento da responsabilidade 
pelo exercício das funções de sua competência com diligência; e (ii) a justificativa de restrição das competências do conselho fiscal, ou das instrumentalidades para exercício, sob o fundamento de que esteja sendo exercida por outro grupo de indivíduos sob a supervisão de outro órgão da companhia (assembleia-geral ou administração).

40. Atribuir ao conselho fiscal essa competência centralizadora da fiscalização da legalidade da atuação da administração nas companhias brasileiras decorre da Lei das Sociedade Anônimas que prevê ser indelegável a competência conferida ao conselho fiscal, nos termos do art. $163, \S 7^{\circ}$ do referido diploma legal.

41. Desse modo, se (i) não se pode suprimi-lo ou delegar a sua competência a outro órgão e (ii) não é eficiente criar uma multiplicidade de órgãos com competências fiscalizatórias justapostas, utiliza-se do arcabouço normativo existente para, por meio de instrumentos estruturais e organizativos, aprimorá-lo de modo a empoderá-lo suficientemente para o cumprimento de sua competência legal.

42. Nesse contexto, defende-se a previsão de regras que contribuam para eficácia da atuação do conselho fiscal, por meio de garantia de (i) independência na indicação e atributos necessários dos membros para exercício da função; (ii) remuneração compatível e autonomia orçamentária para desenvolvimento de suas atividades; (iii) competência ampla para controle da legalidade dos atos praticados por meio ou em nome da companhia e prerrogativas para assegurar seu exercício; e (iv) vinculação de suas decisões, respeitado o procedimento de reexame do tema pelo conselho de administração, mediante decisão fundamentada.

Propõe-se a seguinte estrutura base de funcionamento do conselho fiscal, na qualidade de único órgão responsável pela fiscalização da companhia:

(i) órgão de funcionamento permanente;

(ii) composto por cinco membros, eleitos pela assembleia-geral, sendo:

a) um membro indicado pelos acionistas detentores de ações preferenciais sem direito a voto ou com voto restrito; 
b) um membro indicado pelos acionistas minoritários detentores de ações com direito a voto;

c) um membro indicado pelos demais acionistas;

d) dois membros independentes indicados pelos membros eleitos na forma prevista nos itens anteriores e eleitos pelos acionistas;

(iii) competente para analisar a legalidade de todos os atos praticados por meio ou em nome da companhia;

(iv) munido de:

a) remuneração adequada e compatível com a formação e experiência necessárias ao satisfatório exercício do cargo;

b) orçamento autônomo e fixado anualmente com base em métricas objetivas previamente estabelecidas;

c) autorização para acesso irrestrito a todos os documentos e informações produzidos no âmbito da companhia, em formato aberto e bruto;

(v) competente para, por opinião manifestada pela maioria de seus membros, emitir pareceres acerca da legalidade de quaisquer atos perpetuados pela administração (antes ou após serem executados), bem como sugerir as medidas a serem tomadas. Seus pareceres serão:

a) endereçados ao conselho de administração, ou à assembleia-geral, nas hipóteses em que a lei assim exigir;

b) vinculantes, de modo que o conselho de administração somente poderá deixar de observá-los se deliberar, mediante apresentação de parecer fundamentado que (b.l) contraponha pontualmente todos os 
argumentos apresentados pelo conselho fiscal, (b.2) seja devidamente assinado por todos os membros do conselho de administração que o aprovarem e (b.3) seja levado a registro (e publicado no sistema da CVM, no caso de companhias abertas), acompanhado de cópia integral do parecer do conselho fiscal a que se contrapõe.

(vi) responsável (cada membro individualmente considerado) pelos danos resultantes de omissão no cumprimento de seus deveres e de atos praticados com culpa ou dolo, ou com violação da lei ou do estatuto, nos termos do art. 164 da Lei das Sociedades Anônimas.

43. Entende-se que, mediante essa estrutura preliminar, pode-se delinear um sistema interno de controle efetivo, apto a identificar e prevenir a prática de atos contra a administração pública, por meio ou em nome da companhia. Mais uma vez ressalta-se que a implementação das medidas podem ser dar por meio de introdução de regras estatutárias ou em acordos de acionistas, conforme seja mais adequado à luz da legislação e das características específicas da companhia a que se referem. 


\section{BIBLIOGRAFIA}

1. ADAMS, M. Determinants of audit committee formation in the life insurance industry: New Zealand evidence. Journal of Business Research. New York, v. 38, p. 123, Feb. 1997.

2. ALEXY. Robert. A theory of constitutional rights. Trans. Julian Rivers. Oxford: Oxford University Press, 1985.

3. . On Balancing and Subsumption. Ratio Juris 16 (2003), 433449.

4. Constitutional Rights and Proportionality. Journal for Constitutional Theory and Philosophy of Law, REVUS 22, 55-65, 2014.

5. ARLEN, Jennifer H. Compensation system and efficient deterrence. Maryland Law Review, V. 52, n. 4, 1993.

6. BACKER, Larry Catá. The duty to monitor: emerging obligations of outside lawyers and auditors to detect and report corporate wrongdoing beyond the federal securities laws. St. John’s Law Review. Vol. 77: 919.

7. Transparency Between Norm, Technique and Property in International Law and Governance: The Example of Corporate Disclosure Regimes and Environmental Impacts. Minnesota Journal of International, Winter, 2013.

8. BARCLAY, M.J; HOLDERNESS, C.G. Private benefits from control of public corporations. In Journal of Financial Economics 25, 1989.

9. BEBCHUK, Lucian Arye et all., Stock Pyramids, Cross-Ownership, and Dual Class Equity: The Mechanisms and Agency Costs of Separating Control from Cash-Flow Rights, in Concentrated Corporate Ownership, Randall K. Morcked, 2000.

10. ; ROE, Mark. A Theory of Path Dependence in Corporate Ownership and Governance. Stanford Law Review, v. 52, 1999. 
11. BECHARA, Ana Elisa Liberatore S., FUZIGER, Rodrigo José. A política criminal brasileira no controle da corrupção pública. Estudios Sobre La Corrupción Una Reflexión Hispano Brasileña, Salamanca: Universidade de Salamanca, 2013.

12. BERGLÖF, E.; THADDEN, E. The changing corporate governance paradigm: implications for transition and developing countries. Conference Paper, Annual World Bank Conference on Development Economics, 1999.

13. BERLE, Adolf e MEANS, Gardiner. The Modern Corporation and Private Property, New York: Macmillan, 1932.

14. . The case for increasing shareholder power. In Harvard Law Revenue. 118, 2005.

15. BITTENCOURT, Cesar Roberto. Tratado de Direito Penal - Parte Especial, Volume 05, São Paulo: Saraiva, 2009.

16. BRADBURY, M. E. The incentives for voluntary audit committee formation. Journal of Accounting and Public Policy, v. 9, p. 19-36, 1990.

17. BRAIOTTA, L. Jr. The audit director's guide. New York: John Willey \& Sons, 1981.

18. BRANDÃO, Carlos Eduardo Lessa, FONTES FILHO, Joaquim Rubens; MURITIBA, Sérgio Nunes (org.). Governança corporativa e integridade empresarial: dilemas e desafios. 1ed. São Paulo: Saint Paul Editora, 2017.

19. BULGARELLI, Waldírio. O conselho fiscal nas companhias Brasileiras. São Paulo: Revista dos Tribunais, 1988.

20. Estado, Empresa e Função Social. São Paulo, RT 732, 1996, p. 38-46.

21. Regime Jurídico da proteção às minorias nas S/A. Rio de Janeiro: Renovar, 1998. 
22. CARVAlHOSA, Modesto Souza Barros. Comentários à lei de sociedades anônimas, São Paulo: Saraiva, 2013-2015.

23. CEREZETTI, Sheila Christina Neder. Administradores Independentes $e$ Independência dos Administradores (Regras Societárias Fundamentais ao Estímulo do Mercado de Capitais Brasileiro). In Marcelo Vieira Von Adamek (coord.), Temas de Direito Societário e Empresarial Contemporâneos, São Paulo, Malheiros, 2011, p. 575.

24. Aligning corporate governance private regulation with the public interest: a look at the pitfalls of the Brazilian takeover private regulation. Chicago: American Bar Association, 2012.

25. CHAPUT, Yves (coord.). La direction des sociétés anonymes en Europe: Vers des pratiques harmonisées de gouvernance? Paris: LITEC, 2009.

26. $\mathrm{CHOW}, \mathrm{C} . \mathrm{W}$. The demand of external auditing: size, debt and ownership influences. The Accounting Review. [S.1.], v. 52, p. 272-291, 1982.

27. COFFEE JR., John C. Do norms matter? A Cross-Country Examination of the Private Benefits of Control. Columbia Law School, working paper n. 183. Janeiro, 2001.

28. The Rise of Dispersed Ownership: The Roles of Law and the State in the Separation of Ownership and Control. Yale Law Journal, Vol 111:1, 2001.

29. COLLIER, P. Factors affecting the formation of audit committees in major UK listed companies. Accounting and Business Research. Kingston Upon Thames, v. 23, p. 421, 1993.

30. ; GREGORY, A. Audit committee activity and agency costs. Journal of Accounting and Public Policy, v. 18, p. 311-332, Winter. 1999. 
31. COMPARATO, Fábio Konder. Aspectos jurídicos da macro empresa. São Paulo: Revista dos Tribunais, 1970.

32. ; SALOMÃO FILHO, Calixto. $O$ poder de controle na sociedade anônima. Rio de Janeiro, Forense, 5a ed., 2008.

33. COOLS, S. The real difference in corporate law between the United States and Continental Europe: distribution of powers. Del. K. Cop. L. 30, 2005.

34. DA SILVEIRA, Alexandre Di Miceli; LEAL, Ricardo P.C.; CARVLHAL DA SILVA; Andre; BARROS, Lucas Ayres B. de C. Evolution and Determinants of Firm-Level Corporate Governance Quality in Brazil, 20 de junho de 2007. Disponível em: http://ssrn.com/abstract=995764.

35. DJAN, Yves. Le contrôle de la direction des societés anonymes dans le pays de marché commun. Paris, 1965.

36. EIZIRIK, Nelson. Limites à atuação do conselho fiscal. Revista de Direito Mercantil, Industrial, Econômico e Financeiro. São Paulo: RT, n. 84, 1991.

37. . A Lei das S/A Comentada. São Paulo: Ed. Quartier Latin, 2011.

38. FARIA, José Eduardo. Sociologia Jurídica, Direito e Conjuntura. São Paulo, Saraiva, $2^{\mathrm{a}}$ ed. 2010.

39. DONALDSON, Thomas; PRESTON, Lee E. The stakeholder theory of the Corporation: concepts, evidence and implications. Academy of Management Review, New York, v. 20, n. 1, p. 65-91, 1995.

40. FAMA, E. F.; JENSEN, M. C. Agency problems and residual claims. The Journal of Law and Economics, 1983.

41. FAZZIO JÚNIOR, Waldo. Sociedades Limitadas. São Paulo: Editora Atlas, 2003. 
42. FELO, A. J.; KRISHNAMURTHY, S.; SOLIERI, S. A. Audit committee characteristics and the perceived quality of financial reporting: an empirical analysis, 2003.

43. FERRERO FERRERO, Idoya; ACKRILL, Robert. Europeanization and the Soft Law Process of EU Corporate Governance: How has the 2003 Action Plan Impacted on National Corporate Governance Codes? JCMS: Journal of Common Market Studies, 2016 Volume 54. Number 4. pp. 878-895.

44. FUTURA, Fernanda, DOS SANTOS, Ariovaldo. Comitê de Auditoria versus conselho fiscal Adaptado: a visão dos analistas de mercado e dos executivos das empresas que possuem ADRs. Revista Contabilidade \& Finanças, USP, São Paulo, v. 21, n. 53, maio/agosto 2010.

45. FRAGOSO, Heleno Cláudio. Lições de direito penal. São Paulo: Bushatsky, 1959.

46. GAMBETTA, Diego, Trust, Making and Breaking Cooperative Relations, Department of Sociology, University of Oxford.

47. GARRIGUES, Joaquim. La Sociedad Anonima y el Estado, in Hacia um Nuevo Derecho Mercantil, Madri, 1971.

48. GILSON, Ronald. Controlling shareholders and corporate governance: complicating the corporative taxonomy. ECGI Working Paper $n^{\circ}$ 49, 2005.

49. .; HANSMANN, Henry; PARGENDLER, Mariana. Regulatory Dualism as a Development Strategy: Corporate Reform in Brazil, the United States, and the European Union. Stanford Law Review, v. 63, 2011.

50. GOMES JUNIOR, João Florêncio de Salles. O crime de concussão e sua distinção dos crimes de extorsão e corrupção passiva no direito penal brasileiro. Estudos em homenagem a Vicente Greco Filho, São Paulo: LiberArs, 2014. 
51. GORGA, E. changing the paradigm of stock ownership from concentrated towards dispersed ownership? Evidence from Brazil and consequences for emerging countries. Northwestern Journal of International Law \& Business, v. 29, 2009.

52. GOSHEN, Zohar, HAMDANI, Assaf. Corporate Control and Idiosyncratic Vision. The Yale Law Journal 125:560, 2016.

53. GOWER, Laurence C; DAVIES, Paul L. The Principles of modern company law. London, Sweet \& Maxwell, 1992.

54. GUERREIRO, José Alexandre Tavares. Sociedade anônima: poder e dominação. Revista de Direito Mercantil, Industrial, Econômico e Financeiro, n. 53, jan.mar./1984.

55. Sociologia do Poder na Sociedade Anônima. Revista de Direito Industrial, Econômico e Financeiro, v. 77, p. 50, 1990.

56. HANSEN, Robert G.; LOTT JR., John R. Externalities and corporate objectives in a world with diversified shareholder/consumers. Journal of Financial and Quantitative Analysis, v. 31, 1996.

57. HANSMANN, Henry e KRAAKMAN, Reinier. Reflections on the end of history for corporate law. August 2011. Forthcoming in Abdul Rasheed and Toru Yoshikawa, Eds. Convergence Corporate Governance: Promise and Prospects. PalgraveMacMillan, 2012.

58. ; PARGENDLER, Mariana. The Evolution of Shareholder Voting Rights: Separation of Ownership and Consumption. The Yale Law Journal, vol. 123, 2014.

59. ; MECKLING, William H. Theory of the firm: managerial behavior, agency costs and ownership structure. Journal of Financial Economics, Vol. 3, no. 4, 1976. 
60. . KEAY, Andrew. Accountability and the corporate governance framework: from Cadbury to the UK Corporate Governance, 2012. Disponível em: http://ssrn.com/abstract=2143171

61. HECKELMAN, Jac C.; POWELL, Benjamin. Corruption and the Institutional Environment for Growth. Comparative Economic Studies, 2010, 52, 371-378.

62. HOUSTON, Douglas A. Can corruption ever improve an economy? Cato Journal, Vol. 27, No. 3, 2007.

63. HUNGRIA, Nelson. Comentários ao código penal, Volume IX. Rio de Janeiro: Forense, 1958.

64. IBGC - Instituto Brasileiro de Governança Corporativa. Código Brasileiro de Governança Corporativa. Disponível em: http://conhecimento.ibgc.org.br/Lists/Publicacoes/Attachments/21148/Codigo_Brasileiro_ de_Governanca_Corporativa_companhias_Abertas.pdf.

65. Pratique ou explique: análise quantitativa dos informes das companhias abertas brasileiras. Disponível em: http://conhecimento.ibgc.org.br/Lists/Publicacoes/Attachments/23995/pesquisa_pratiqueex plique_novo.pdf.

66. JOHNSON, Noel D.; RUGER, William; SORENS, Jason; YAMARIK, Steven. Corruption, regulation, and growth: an empirical study of the United States. Springer-Verlag Berlin Heidelberg, 2013.

67. KAUFMANN, Daniel; SIEGELBAUM, Paul. Privatization and corruption in transition economies. Journal of International Affairs, Columbia University School of International Public Affairs. 50.2, 1997.

68. KEENAN, David; COOPER, Deborah Jane, LEBOWITZ; David \& LERER, Tamar. The Myth of Prosecutorial Accountability After Connick v. Thompson: Why Existing Professional Responsibility Measures Cannot Protect Against Prosecutorial Misconduct. Yale Law Journal, 121:203, 2011. 
69. KRAAKMAN, Reinier; Armour, John; DAVIES, Paul; ENRIQUES, Luca, HANSMANN, Henry, HERTIG, Gerard; HOPT, Klaus, KANDA, Hideki, PARGENDLER, Mariana; RIGNE, Wolf-Georg, ROCK, Edward. A anatomia do direito societário: uma abordagem comparada e funcional. São Paulo: Editora Singular, 2018.

70. KRUEGER, Anne O. The Political Economy of the Rent-Seeking Society. The American Economic Review, Vol. 64, No. 3 (Jun.,1974), pp. 291-303.

71. LEFF, Nathaniel H. Economic Development Through Bureaucratic Corruption. The American Behavioral Scientist, November 1964, 8-14.

72. LOBO, Jorge. Princípios de governança corporativa. In Revista de Direito Mercantil, Industrial, Econômico e Financeiro. Nº142. São Paulo, Malheiros.

73. LOPES, Alexsandro Broedel, COELHO, Antonio Carlos, BHIMANI, Alnoor, TRAPP, Adriana Cristina. The supervisory board as an alternative corporate governance mechanism: evidence from Brazil. Denver, 2011.

74. MACHADO, Ana Mara França. Sistema brasileiro anticorrupção: internacionalização do direito e variantes nacionais. Dissertação (Mestrado), São Paulo, 2010.

75. MAHR, Till G.; NOWAK, Eric; ROTT, Roland. The (Ir)Relevance of Disclosure of Compliance with Corporate Governance Codes - Empirical Evidence from the German Stock Market. Journal of Institutional and Theoretical Economics JITE, Volume 172, Number 3, pp. 475-520, September 2016.

76. MAURO, Paolo. Corruption and Growth. Quarterly Journal of Economics, 110: 681$712,1995$.

77. MELO, Débora Thaís de. Os bens jurídicos ofendidos pela corrupção e o problema específico dos bens jurídicos coletivos. In: Santos, Cláudia Cruz; Bidino, Claudio; Melo, Débora Thaís de. A corrupção. Reflexões (a partir da Lei, da Doutrina e da 
Jurisprudência) sobre o seu regime jurídico-criminal em expansão no Brasil e em Portugal. Coimbra: Coimbra Editora, 2009.

78. MENON, K.; WILLIAMS, J. D. The use of audit committee for monitoring. Journal of Accounting and Public Policy. v. 13, p. 121-139, 1994.

79. MÉON, Pierre-Guillaume; SEKKAT, Khalid. Does corruption grease or sand the wheels of growth? Public Choice (2005) 122, p. 69-97.

80. MORELLI, Denis. Os órgãos técnicos e consultivos da sociedade anônima. Dissertação de mestrado apresentada ao Departamento de Direito Comercial da Universidade de São Paulo, 2012.

81. MUNHOZ, Eduardo Secchi. Quem deve comandar a companhia? Alocação do poder empresarial: sistema de freios e contrapesos. In Estudos em Homenagem a Modesto Carvalhosa. São Paulo, Saraiva, 2012.

82. NERANTZIDIS, Michail. Measuring the quality of the "comply or explain" approach: Evidence from the implementation of the Greek corporate governance code, Managerial Auditing Journal, Vol. 30 Issue: 4/5, pp.373-412, 2015.

83. NYE, J.S. Corruption and Political Development: a cost-benefit analysis. The American Political Science Review, vol. 61, n. ${ }^{\circ}$ 2, 1967.

84. OCDE - Organização para a Cooperação e Desenvolvimento Econômico. Princípios de Governança Corporativa da OCDE. OCDE, 2004.

85. Typologies on the Role of Intermediaries in International Business Transactions, Final Report. OECD (2009). Disponível em: hdr.undp.org/en/statistics/hdi.

86. ; G20. Protection of Whistleblowers: Study on Whistleblower Protection Frameworks, Compendium of Best Practices and Guiding Principles for Legislation, 2011. Disponível em: www.oecd.org/daf/anti-bribery/48972967.pdf 
87. . The World Bank (2012). Identification and Quantification of the Proceeds of Bribery: Revised edition, February 2012. OECD Publishing. Disponível em: http://dx.doi.org/10.1787/9789264174801-en

88. . Issues Paper on Corruption and Economic Growth. G20/OECD (2013). Disponível em: www.oecd.org/g20/topics/anticorruption/issues-paper-on-corruption-and-economic-growth.pdf

89. OECD Foreign Bribery Report An Analysis of the Crime of Bribery of Foreign Public Officials, OECD Publishing, 2014. Disponível em: http://dx.doi.org/10.1787/9789264226616-en

90. OECD Good Practice Guidance on Internal Controls, Ethics and Compliance. Disponível em: www.oecd.org/investment/anti-bribery/antibriberyconvention/44884389.pdf.

91. OSTROM, Elinor. Beyond Markets and States: Polycentric Governance of Complex Economic Systems. Nobel Prize Lecture, 2009.

92. PELEIAS, Ivan Ricardo e LOURENÇO, Maria Cristina. Conselho fiscal responsabilidade com a sociedade e os investidores. São Paulo: Atlas, 2010.

93. PILAGALLO, Oscar. Corrupção: entrave ao desenvolvimento do Brasil. Rio de Janeiro, Elsevier, 2013.

94. PINCUS, K.; RUSBARSKY, M.; WONG, J. Voluntary formation of corporate audit committees among NASDAQ firms. Journal of Accounting and Public Policy, 1989.

95. PIOT, C. The existence and independence of audit committees in France. Accounting and Business Research. United Kingdom, v. 34, n. 3, p. 223-246, 2004.

96. PISTOR, Katharina. Codetermination: A Sociopolitical Model with Governance Externalities. In: BLAIR, Margaret M.; ROE, Mark J. Employees and Corporate Governance. Washington D.C: Brookings Institution Press, 1999. 
97. PONTES, Evandro Fernandes. O conselho fiscal nas companhias Abertas Brasileiras. São Paulo: Almedina, 2012.

98. PORTUGAL GOUVÊA, Carlos Pagano Botana. The third bank of the river: democracy and its corruption after liberalization reforms in Latin America. Thesis (LL. M.), Harvard Law School, 2004.

99. . The Managerial Constitution: The Convergence of Constitutional and Corporate Governance Models, July, 2013. Disponível em: http://papers.ssrn.com/sol3/papers.cfm?abstract_id=2288315.

100. PRADO, Mariana Mota; CARSON, Lindsey D. Brazilian Anti-Corruption Legislation and its Enforcement: Potential Lessons for Institutional Design. International Research Initiative on Brazil and Africa - IRIBA, School pf Environment, Education and Development, University of Manchester, 2014.

101. Using institutional multiplicity to address corruption as a collective action problem: Lessons from the Brazilian case. The Quarterly Review of Economics and Finance 62 (2016), 56-65.

102. The Brazilian Clean Company Act: Using Institutional Multiplicity for Effective Punishment. Osgoode Legal Studies Research Paper Series, 119, 2016.

103. PROENÇA, José Marcelo Martins; FINKELSTEIN, Maria Eugênia Reis (Org.). Direito societário: gestão e controle. São Paulo: Saraiva, 2008.

104. QUAH, Jon S.T. Governance and Corruption: Exploring the Connection. American Journal of Chinese Studies. Vol. 16:119, October, 2019, 119-135.

105. RAINSBURY, E. A.; BRADBURY, M. E.; CAHAN, S. F. Firm characteristics and audit committees complying with 'best practice' membership guidelines. Accounting and Business Research. United Kingdom, v. 38, n. 5, p. 393-408, 2008. 
106. ROSE, Caspar. Firm performance and comply or explain disclosure in corporate governance. European Management Journal 34, 202-222, Elsevier, 2016.

107. ROSE-ACKERMAN, Susan. Corruption: A Study in Political Economy, New York: Academic Press, 1978.

108. Corruption and Government: Causes, Consequences and Reform. New York: Cambridge University Press, 1999.

109. ; SOREIDE, Tina. International Handbook on the Economics of Corruption, vol I, vol II, Edward Elgar Pub, 2012.

110. ; CARRINGTON, Paul. Anti-Corruption Policy: Can International Actors Play a Constructive Role? Yale Law School, John M. Olin Center for Studies in Law, Economics, and Public Policy Research Paper No. 440, 2011.

111. ROSENBLUM, Steven A. Hedge fund activism, short-terminism and a new paradigm of corporate governance. 126 Yale L.J. F. 538 (2017).

112. RUBIO, Jesus. Curso de Derecho de Sociedades Anonimas, $3^{\mathrm{a}}$ ed., Madri, 1974.

113. SAlOMÃO FILHO, Calixto. O novo Direito Societário. São Paulo, Malheiros Editores, $4^{\mathrm{a}}$ edição, 2011.

114. Teoria crítico-estruturalista do direito comercial. $1^{\mathrm{a}}$ ed., São Paulo, Marcial Pons, 2015.

115. SANDEL, Michael J. What money can't buy: the moral limits of markets. London, Allen Lane, New York, 2012.

116. SANTOS, Aldomar Guimarães dos. Comitê de Auditora: uma análise baseada na divulgação das informações de empresas brasileiras. Dissertação (Mestrado em Controladoria e Contabilidade: Contabilidade) - Faculdade de Economia, Administração e Contabilidade, Universidade de São Paulo, São Paulo, 2009. 
117. SELIGSON, MA. The impact of Corruption on regime legitimacy: a comparative study of four Latin American countries. Journal of Politics. 64, 2, 408, May 2002.

118. SHLEIFER, Andrei; VISHNY, Robert W. Corruption. Quarterly Journal of Economics. 108.3, Oxford University Press, 1993.

119. SIEYÈS, Emmanuel Joseph. Qu'est-ce que le Tiers état? Paris, 1789.

120. SILVA SÁNCHEZ, Jesús-María. La expansión del Derecho penal. Aspectos de la política criminal en las sociedades post industriales. Madrid: Civitas, 1999.

121. SILVA, Thiago José da, CAMARGO, André Antunes Soares de. Conselheiros Independentes: status e proposições. Revista de Direito das Sociedades e dos Valores Mobiliários, Almedina, 2015.

122. SILVEIRA, Alexandre di Meceli da. Governança corporativa no Brasil e no mundo. Rio de Janeiro: Elsevier, 2010.

123. SILVEIRA, Renato de Mello Jorge. A ideia penal sobre a corrupção no Brasil: da seletividade pretérita à expansão de horizontes atual. Estudios Sobre La Corrupción Una Reflexión Hispano Brasileña, Salamanca: Universidade de Salamanca, 2013.

124. SOLTVEDT, Ida Folkestad. Soft Law, Solid Implementation? The Influence of Precision, Monitoring and Stakeholder Involvement on Norwegian Implementation of Arctic Council Recommendations. Arctic Review on Law and Politics, Vol. 8, 2017, pp. 73-94.

125. SOUZA, Luciano Anderson de. Corrupção: novos desafios jurídico-penais em torno de um antigo grave problema, Livro homenagem a Miguel Reale Júnior, Rio de Janeiro: G/Z, 2014.

126. SPAHN, Elizabeth. Nobody gets hurt? Georgetown Journal of International Law, vol. 41, 2010, 862-905. 
127. STRINE, Leo E., Jr. Who Bleeds When the Wolves Bite? A Flesh-and-Blood Perspective on Hedge Fund Activism and Our Strange Corporate Governance System, 126 Yale L.J. 1870 (2017).

128. SUNDFELD, Carlos Ari (org.). Direito Administrativo Econômico. $1^{\circ}$ ed. São Paulo: Malheiros, 2000.

129. TANTALO, C.; PRIEM, R. L. Value creation through stakeholder synergy. Strategic Management Journal, v.37, n.2, p.314-329, 2014.

130. TURLEY, S.; ZAMAN, M. The corporate governance effects of audit committees. Journal of Management and Governance., v. 8, n. 3, p. 305-332, 2004.

131. URTIAGA, María Gutierrez, SAEZ, Maribel. Deconstructing Independent Directors. Working Paper $n^{\circ}$ 186/2012.

132. VON ADAMEK, Marcelo Vieira. Responsabilidade dos Administradores de S.A. e as Ações Correlatas. São Paulo, Saraiva, 2009.

133. WIEDEMANN, Hebert. Gesellschaftsrecht I- Grundlagen. Munique: Editora Beck, 1980. Tradução de Erasmo Valladão Azevedo Novaes e França, in Temas de Direito Societário, Falimentar e Teoria da Empresa, Malheiros, 2000.

134. ZHAO, John Hongxin; KIM, Seung H.; DU, Jianjun. The Impact of Corruption and Transparency on Foreign Direct Investment: An Empirical Analysis. Management International Review, vol. 43, 2003. 